\title{
A supervisão institucional como intervenção sócio-analítica
}

\section{Cecília Maria B. Coimbra}

Universidade Federal Fluminense

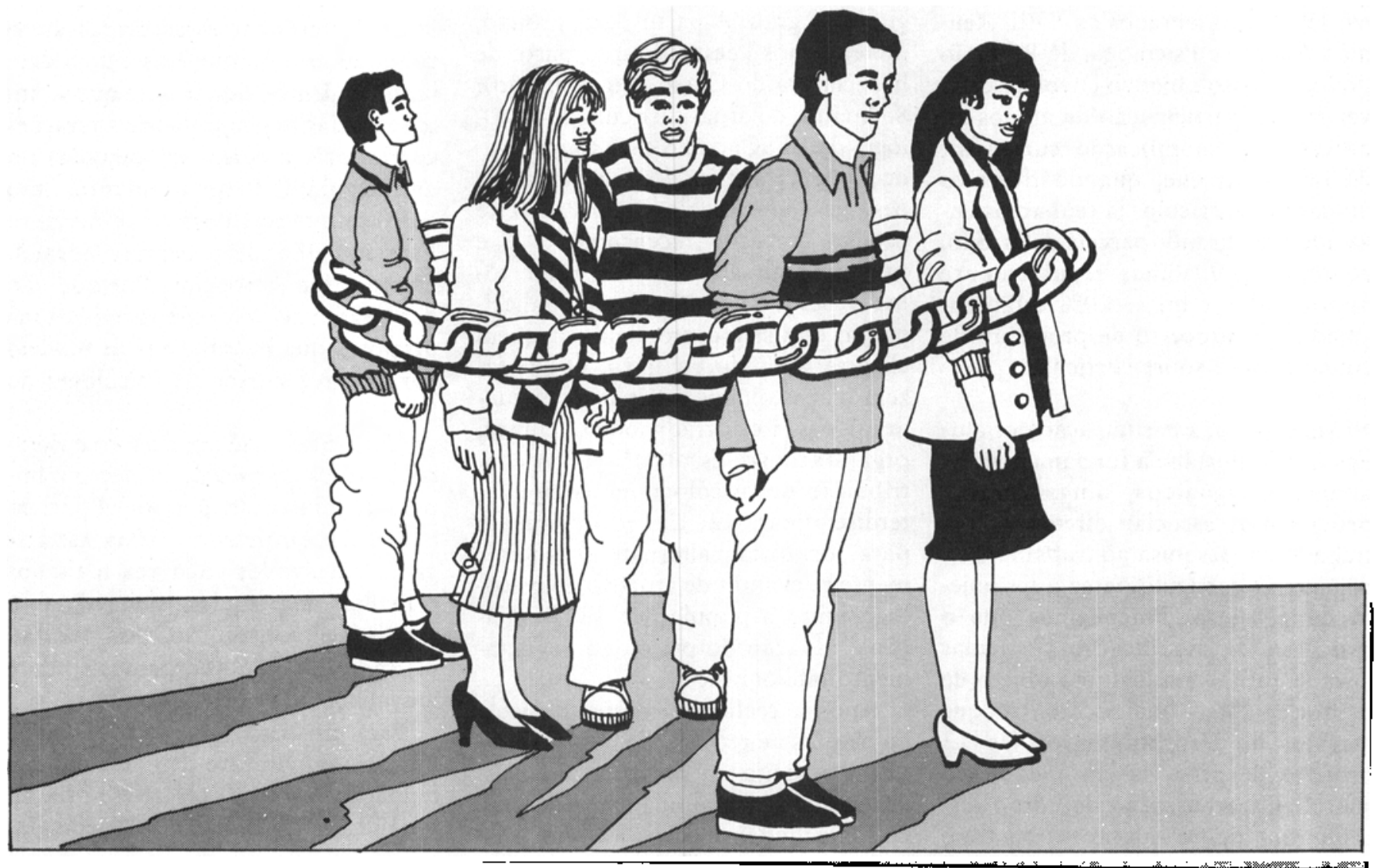

A o falar sobre supervisão torna-se importante nāo a entendermos em abstrato, ou seja, não a colocarmos como uma técnica neutra. A supervisão vista como récnica de acompanha. mento e orientação a futuros profissionais em suas tarefas práticas, inevitavelmente cai nas perigosas artimanhas da neutralidade, do tecnicismo, do nāo saber e do instituído.

Pude constatar ao longo de vários anos como supervisora de estagiários em Psicologia, trabalhando em diferentes universidades, uma série de en26 PSICOLOGIA, CIÊNCIA E PROFISSÃO quadres que os suprevisores seguem. Dentre os mais comuns estão:

- aquele que poderíamos chamar de autoritário, ou seja, o que considera, como o próprio nome indica, o supervisor como tendo uma visão super. Aquele que tudo vê, tudo percebe, tudo sabe. $O$ estagiário, reduzido àquele que nada pertence e nada sabe, necessita, portanto, das "iluminadas" e "sábias" verdades daquele que o orienta. Isso acarreta perigosas conseqüências na própria formação do profissional.
De um modo geral, constatamos que muitos estagiários tornam-se verdadeiras cópias de seus supervisores, o que, em realidade, os gratifica bastante. As palavras de seu mestre são reproduzidas fielmente em seus trabalhos, em seus atendimentos. Reforçase com isso o poder do instituído, do saber, daquele que detém a competência e isso facilmente é reproduzido nas relações que estes estagiários mantêm com as instituições em que atuam e/ou clientes que atendem. Criam-se, assim, dispositivos de poder fortemente introjetados, pois es- 
tão $\mathrm{em}$ consonância e muito bem articulados com tudo o que o nosso sistema educacional prega.

Vê-se, portanto, como este enquadre de supervisão está coerente com o desenvolvimento do saber psi no Brasil, produto do autoritarismo e do período ditatorial. Está também articulado com a finalidade para a qual a supervisão foi instituída, ou seja, ela foi colocada nos curriculos, foi pro. duzida, como mais um dispositivo de controle sobre os alunos e tem exercido muito bem tal função.

Em todo o curso de Psicologia um dos aspectos mais veiculados de modo sutil ou, muitas vezes, de forma bem clara refere-se ao poder e à onipotência do psicólogo. Com esta prática de supervisão coroa-se todo este processo: através de seu supervisor esta superioridade, como também a infantilização do estagiário e, portanto, sua incompetência são deixados bem claros.

$O$ segundo enquadre em supervisão poderia ser chamado de liberal. Seria aquele de inspiração humanista, não diretivo e pseudamente democrático, onde o supervisor escamoteando as relaçōes de poder existentes, afirma-se ser un igual a seus estagiários. É a mesma posição ingênua e acrítica daqueles que, ao fazerem um trabalho de cunho popular, afirmam que nada têm a ensinar ao povo, pois tudo o que vem dele é puro e verdadeiro. (Ver nota 1 na Bibliografia)

Neste tipo de atuação é muito en fatizado o trabalho grupal, através de dinâmicas de grupo e sensibilizações, o que é perfeitamente compreensivel para se caracterizar seu aspecto "igualitário" e "democrático". Em realidade, não é por acaso que as dinâmicas de grupo se iniciaram nos trabalhos nas empresas a partir da década de 30, com o desenvolvimento do capitalismo liberal. (Ver nota 2 na Bibliografia). Sabemos que é uma forma de fazer funcionar no vazio, algumas forças que podem se tornar instituintes $e$, portanto, perigosas. "Criam-se essas válvulas de segurança, esses dispositivos que canalizam os descontentes e fazem funcionar as forças instituintes em circuito fechado. O fluxo... é cortado, passado por alto e deixa de operar... Tal é o sentido das ideologias não diretivas, participacionistas, sustentadas pela ideologia grupista que funciona como verdadeira polícia cultural e estatal e, por trás dela, toda a psicologia contemporânea na qual o grupismo repousa alegremente" (Bernard, 1973, p.41-42). Assim sensibiliza-se, criticase e questiona-se, desde que seja dentro de certos limites, de determinado território. E, tudo continua como antes, vendendo-se a ilusāo de participação e os estagiários se sentindo felizes, respeitados e acreditando que estāo sendo sujeitos em um processo de transformação.

Penso que estes e outros enquadres que se tem visto em relação à supervisão tornam-se verdadeiras armadilhas porque não conseguem equacionar três importantes dimensões deste trabalho: o político, o social e o institucional. Sem elas a supervisão é percebida como um processo natural, neutro e puramente técnico.

Dentro de um referencial da Análise Institucional, podemos entender a supervisão não como uma técnica neutra e um processo natural, mas sim dimensionada histórica, política, social e institucionalmente.

A dimensão polírica nos mostra que os enquadres colocados anteriormente não são neutros. Como mostramos, servem a claros objetivos que interessam ao Estado e ao fortalecimento dos micropoderes instituídos. Contestamos com isso os mitos veiculados e reforçados por todo o nosso sistema educacional e por nossa formação social.

A dimensão social nos possibilita entender a nossa implicação. Ou seja, se a supervisão é uma prática política temos implicaçōes claras com o social. Estamos com o nosso trabalho sustentando e reforçando o que nos cerca, ou pretendemos transformá-lo, colocá-lo em crise e fortalecer novos encontros e agenciamentos? Penso que essa implicação se torna bem clara, à medida que se mostra o lugar social e político no qual o supervisor se inscreve e do qual fala.

A dimensão institucional nos faz entender a supervisão como uma das instituiçōes que instrumentam a formação profissional do psicólogo. Ou seja, se tomamos, segundo a Análise
Institucional,o conceito de instituição não como o lugar onde o jurídico se manifesta, mas onde as relações de produção estão instituídas de maneira aparentemente necessária, natural e eterna, entendemos, por exemplo,que na universidade temos uma série de instituições presentes: a formação; a profissão-psicólogo com suas áreas de competência, a supervisão, etc. (Ver nota 3 na Bibliografia).

Aqui torna-se fundamental a noção de transversalidade para entendermos que a instituição da supervisão é determinada e atravessada por uma série de outras instituições. Ao trabalhar com um grupo de supervisão é importante que se desvende e aponte as instituiçōes que ali estão instrumentalizadas, pois assim, ao mesmo tempo em que se discute o próprio grupo como instituição, também se discute a própria instituição supervisão e outras. Quer dizer, "tenta-se apontar para as múltiplas vozes que atravessam e são atravessadas nas instituições com as quais... (se) trabalha, pois não há relações lineares de causa e efeito, umas ações determinando outras; o que há são acontecimentos que se produzem na interrelação contextual, efeitos produzindo outros e mais outros". (Coimbra, Lobo e Barros, 1987, p. 53).

Entendemos que há que se inventar dispositivos para se transformar o grupo de supervisão de grupo assujeitado ou grupo objeco,em grupo sujeito. (Ver nota 4 na Bibliografia.) Ou seja, dispositivos que tentem desarrumar, desbloquear de um modo geral os grupos instituídos, os grupos que conhecemos, que são meramente objetos de outros grupos ou instituiçōes, recebendo suas determinações, seu funcionamento e se ajustando a essas instituições. Nesses grupos instituídos, os membros sảo identificados com as instituições que determinam sua existência e atravessam sua estrutura. Neles predomina a regra do não saber e o não recontecimento de suas impliçaçōes institucionais. Aqui fica claro que estamos falando das supervisões já citadas de enquadres bem marcados.

Em uma supervisão que chamaríamos institucional, propomos intervir nos grupos instituídos para que se transformem em outros, onde as imPSICOLOGIA, CIÉNCIA E PROFISSÁO, 27 
plicações institucionais sejam desveladas, onde uma outra fala seja produzida, onde as categorias marginais, subterrâneas e reprimidas estejam presentes e possam se expressar. Isto quer dizer que os grupos sujeitos assumem seus próprios desejos e instituem novas relaçōes sociais, tornando-se capazes de romper com os processos identificatórios com outras instituiçōes que criam o nào saber sobre si mesmos e sobre seus próprios funcionamentos.

Trata-se, portanto, de romper estes enquadres modeladores que tanto o supervisor quanto o estagiário trazem. Enquadres que, em realidade, são territórios fechados com lugares muito bem demarcados, ou seja, o lugar do supervisor (o do saber) e do estagiário (o do não-saber). Há que, no processo de supervisão, tentar a fragmentaçào dos centros de poder $e$ saber, fortalecendo a circulação e a expansão dos fluxos presentes.

Com isso estamos enfarizando a importância da análise de nossa implicação enquanto supervisores. Ou seja, não é pelo fato de se tentar quebrar os micro-poderes instituídos que se cairia no democratismo ou liberalismo já anteriormente citados. Ao contrário, o lugar do poder e suas relaçōes não são negados, mas afirmados; não no sentido de marcar cada vez mais este espaço, mas no movimento de expandi-lo para que seja por outros apropriado, para que a circulação ocorta. Em momento algum, o lugar social e político no qual se encontra o supervisor é escamoreado. É principalmente debatido com o grupo como tal lugar está marcado, de que maneira ele é ocupado e, portanto, que implicaçōes temos nós com ele.

Com tudo isso, entendemos que o grupo de supervisão possa se tornar uma força instituinte e não simplesmente a reprodução do instituído. Para o instituinte não há cercas territoriais, mas territórios provisórios, onde a circulação tende a se expandir.

Nesta supervisão-intervençāo, o trabalho grupal permite a criação de situaçōes que se tornam analisadoras do próprio processo grupal enquanto instituição e das demais instituições que ali se apresentam.

Isto traz importantes efeitos, pois 28 PSICOLOGIA, CIÉNCIA E PROFISSÃO

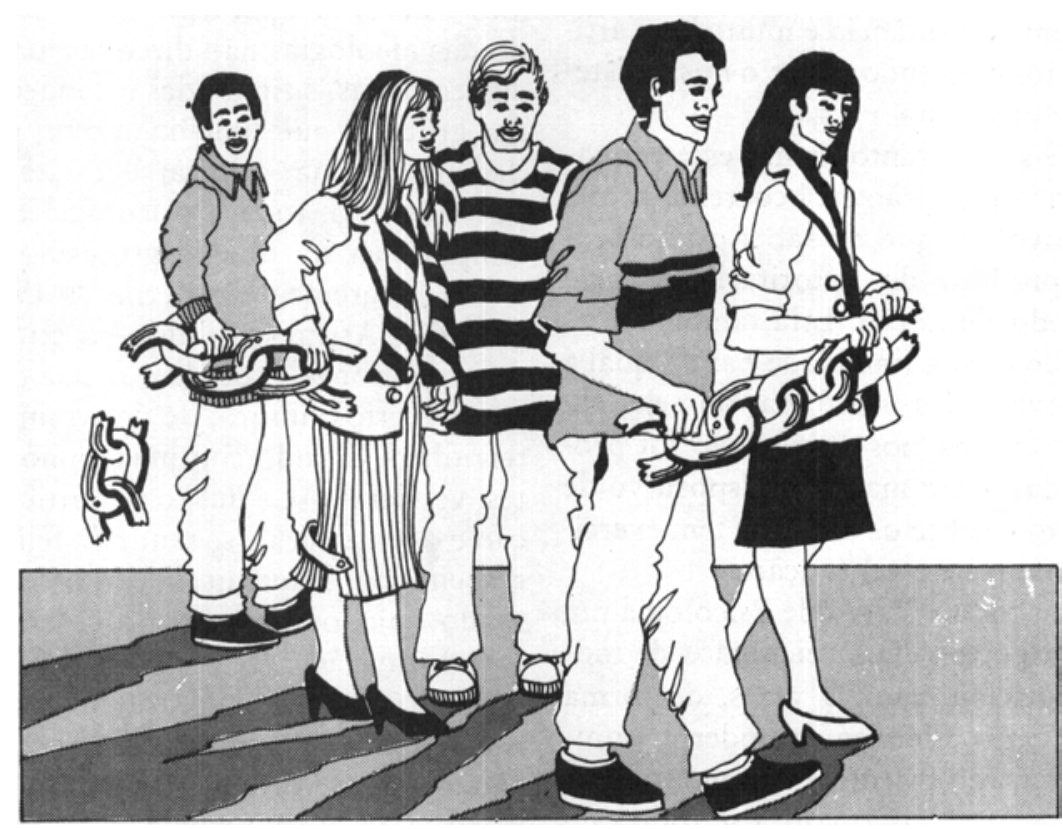

desnuda-se o caráter natural e eterno das instituiçōes de um modo geral e, em particular, da própria instituição supervisāo, demonstrando-se que são criações datadas historicamente. Por outro lado, realimenta-se o estagiário nos trabalhos que irá desenvolver em outras instituiçōes, em outros grupos, ou mesmo em atendimentos individuais.

Talvez seja ilustrativo descrever aqui os efeitos que a leitura desse texto produziu en um grupo de estagiários com o qual trabalho. Com os debates ficou claro que estávamos com essa supervisão-intervençāo conseguindo desarrumar os centros de poder instituídos naquele grupo. Percebemos que as análises e sugestões feitas em relação aos trabalhos realizados circulavam por todo o grupo, não se cristalizando na figura do supervisor. Chegou-se a mostrar que em alguns momentos, principalmente nos grupos de estudo, a coordenação esteve nas mãos de um determinado estagiário e que muitos textos a serem debaridos foram iniciativa e sugestão do próprio grupo. Este debate nos levou a aprofundar as funçōes de um coordenador de grupo, seus limites e em que situações ele sai de cena.

Com tudo isso, pretendemos mostrar que a supervisão não é somente aquela que nos tem sido apresentada do ponto de vista do instituído. Outros caminhos podem ser percorridos e tentados. E, é apostando nisso que ousamos pensar um outro curso para a supervisão. "Foram as práxis dos homens que fundaram as instituiçōes, são suas práxis que as mantêm, transformam ou as colocam em crise." (Evrard, 1973, p. 50). É, acrescentaríamos nós, também através da nossa práxis que ousamos inventar outras. Nâo no sentido de encontrar um outro modelo ou mesmo uma proposta de rerceira via para nosso trabalho. Afirmamos,sim, que, ao percorrermos tal caminho, estamos realizando uma intervenção, estamos produzindo uma série de acontecimentos e, principalmente, estamos desarrumando o instituído.

NOTAS E REFERENCIAS BIBLIOGRÁFICAS '1' Sobre este aspecro ver alguns trabalhos de CARLOS RODRJGUES BRANDÄO E MARI-

LENA CHAUÍ acerca dos diferentes conceitos de culrura populat.

'2'Sobre este ponto é importante consultar o livro de MAURICIO TRATENBERG; Burocracia \& Ideologia, SP, Brastliense.

3 : Sobre este assunto ver o trabalho de Heliand de B.CONDE RODRIGUES e Vera Lucia B. DE SOUZA. A Análise Instirucional e a Profissiona. lizaçāo do Psicólogo in Análise Institucional do Brasil - RJ Ed. Espaço e Tempo, 1987, 17-36. (4) Ver sobre isso GUATTARI, Félix-PsychanaJyse et Transuersalite- Paris, Maspero, 1972. BERNARD, Michel- Las Condiciones del Gropo de Acción, in Amalisis Institucional y Socioanálisis - México, Ed. Xueva Imagem. 1973. P. 41.42

COLMBRA, Cecilia, M.Bouças; LOBO, Lilia F - BARROS. Regiria D.BENEVIDES-A Instituiçăo da Supervisāo: análise e implicaçōes in $A$ nálise Institucional no Brasil. RJ, Ed. Espaço e Tempo, 1987, P. 53.

EVRARD. Pierre F. - Las Manos Puras. in Análisis Institucional y Socioanálisis - Me xico. Ed. Nueva lmagem, 1973, p. 50. 